Middle East Journal of Science(MEJS)

\title{
DETERMINATION OF BIOGAS VALUES FOR TOMATO WASTES USING HOHENHEIM BATCH TEST METHOD
}

\section{Serdar $\ddot{U} c ̧ o k^{I}$ Ali Aybek}

${ }^{1}$ Kahramanmaraş Sütçü İmam Üniversitesi, Ziraat Fakültesi, Biyosistem Mühendisliği Bölümü, 46100, Kahramanmaraş, Türkiye

*sucok@ksu.edu.tr

: Nowadays, biogas technology applications are gradually increasing worldwide due to the economic and environmental benefits. Many researches and studies related to the determination of the biogas potential of waste organic materials have been carried out in the recent years. Studies to determine the specific methane potential of organic waste materials have a great importance for both design and economical operation of the biogas plants.Energy potential that will be recovered from organic wastes are substantial in our country.Thanks to biogas plants gathering vegetable-fruit wastes and other organic wastes are planned to produce significant amount of renewable energy in our country markets. Owing to the use of organic wastes, the disposal of waste as well as energy production, soil, water, air pollution in terms of environmental protection are also minimized. On the other hand, the organic wastes produced from plants can also be utilised as fertilizer in vegetable production. In this study, the cumulative biogas and methane productions of tomato wastes were experimentally determined with HBT (Hohenheim Batch Testing) method. Biogas and methane yields of tomato wastes were found as 0.687-0.695 Nm3/ $\mathrm{kg}$ OKM and 0.364-0.374 $\mathrm{Nm} 3 / \mathrm{kg}$ OKM respectively. Obtained results for biogas production has importance.

Key words: Biogas, tomato wastes, HBT 


\title{
DOMATES ATIKLARININ BIYOGAZ DEĞERLERININ HOHENHEIM BATCH TEST METODU KULLANILARAK BELIRLENMESI
}

\begin{abstract}
Günümüzde biyogaz teknolojisi uygulamaları ekonomik ve çevresel yararlarından dolayı dünya genelinde gittikçe artmaktadır. Bundan dolayl, son yıllarda organik madde atıklarının biyogaz potansiyelinin belirlenmesiyle ilgili birçok araştırma ve inceleme yapılmıştır. Organik madde atıklarının özgül metan potansiyelinin belirlenmesine yönelik yapılan çalışmalar, biyogaz tesislerinin hem dizayn hem de ekonomikliği açısından büyük bir öneme sahiptir. Ülkemizde organik atıklardan geri kazanılabilecek enerji potansiyeli oldukça yüksektir. Ülkemizin birçok yerleşim birimlerindeki pazarlarda sebze ve meyve atıklarından ve diğer organik atıklardan biyogaz elde eden tesisler sayesinde önemli miktarda enerji kazanımı söz konusu olabilecektir. Organik atıkların kullanımı, enerji üretiminin yanında atı̆̆ın bertaraf edilmesinden dolayl, çevresel koruma açısından toprak, su ve hava kirliliği oluşumunu da en aza indirgemektedir. Diğer taraftan tesislerden üretilen organik atıklar ise bitkisel üretimde gübre olarak da değerlendirilebilir.Bu çalışmada, domates atıklarının kümülatif biyogaz ve metan üretimleri, HBT (Hohenheim Batch Test) yöntemi ile, deneysel olarak belirlenmiştir. Domates atıklarının biyogaz verimleri $0.687-0.695 \mathrm{Nm} 3 / \mathrm{kg}$ OKM, metan verimleri ise 0.364-0.374 Nm3/kg OKM arasinda bulunmuştur. Elde edilen sonuçlar; biyogaz eldesi için önemli görülmektedir.
\end{abstract}

Anahtar Kelimeler: Biyogaz, domates atıkları, HBT

\section{Giriş}

Günümüzde yönetimi ve denetimi giderek önem kazanan enerji, kalkınmışlı̆̆ın ve gelişmişliğin bir ölçütü olarak kabul edilmektedir. Son yıllarda artan nüfusa bağlı olarak enerjiye olan ihtiyaç da artış göstermektedir. Teknolojideki son gelişmeler ve fosil yakıt kaynaklarının her geçen gün azalması ile enerji temininde yenilenebilir enerji kaynaklarına olan ilgi artmaktadır.

Yenilenebilir enerji kaynakları, fosil enerji kaynaklarına alternatif olarak kullanılabilen ve doğal ortamda varolan enerji akışından elde edilen kaynaklardır. En önemli yenilenebilir enerji kaynakları güneş, rüzgar, su, jeotermal ve biyokütle olarak sıralanabilir[1].

Yenilenebilir enerji kaynakları arasında biyokütle teknolojisi, teşviklerden dolayı son yıllarda yoğun ilgi görmektedir. Biyokütle, direkt olarak yanabilen veya yakıtlara dönüştürülebilen odun ve diğer bitkiler ya da hayvan atıkları olarak tanımlanabilir [2]. Başka bir tanımla biyokütle, biyolojik kökenli fosil olmayan organik madde kütlesidir. Kaynăg tarım ve orman ürünleri, bitkisel artıklar, hayvansal atıklar, 
deniz bitkileri, endüstriyel ve evsel atıklar olan biyokütle, ekonomik ihtiyaçlara cevap verebilen, çevre dostu, yenilenebilir ve yerel bir enerji kaynağıdır[3-5]. Biyokütleden biyoetanol, biyogaz, biyodizel, odun briketi ve birçok yakıt türü elde edilmektedir[6].

Biyokütle kaynaklardan biyogaz üretimi, doğrudan yakma dışında en basit ve en etkili değerlendirme yöntemidir. Başta Çin ve Hindistan olmak üzere Tayland, Filipinler, Kore, İsviçre, ABD ve Almanya gibi birçok ülkede uygulanmaktadır. Tarımsal faaliyetler sonucunda yetiştirilen veya atık olarak geriye kalan bitkiler, insanların atık olarak ortaya çıkarttığı organik çöpler, hayvan gübreleri, şeker ve gıda sanayinin faaliyetleri sonucu oluşan melas ve meyve posaları, arıtma çamurları, şeker endüstrisi atıkları, kağıt sanayi atıkları ve mezbahane atıkları gibi çeşitli organik maddelerin, havasız bir ortamda biyokimyasal dönüşümler sonucu bakteriler tarafından parçalanmasıyla, bileşiminde metan, karbondioksit, hidrojen sülfür, amonyak, azot, hidrojen ve su buharı bulunan biyogaz üretimi gerçekleştirilir (Akova, 2008). Biyogaz; organik bazlı atıkların oksijensiz ortamda fermentasyonu sonucu oluşan renksiz-kokusuz, havadan hafif, parlak mavi bir alevle yanan ve bileşiminde organik maddelerin bileşimine bağlı olarak yaklaşık; \%40-70 metan, \%30-60 karbondioksit, \%0-3 hidrojen sülfür ile çok az miktarda azot ve hidrojen bulunan bir gaz karışımıdır (Arkutman, 2003). Biyogaz; yoğunluğu $0,83 \mathrm{~g} / \mathrm{L}$, oktan sayısı yaklaşık olarak 110 , yanma sıcaklığ $700 \mathrm{oC}$, alev sıcaklığ $870 \mathrm{oC}$ olan bir gazdır. Biyogazın bileşimi, elde edildiği organik maddenin cinsine ve fermentasyon şekline bağlı olarak değişir (Bayrakçeken, 2007). Biyogaz teknolojisinde kullanılan organik kökenli atıklardan (bitkisel atıklar, şehir ve endüstriyel atıklar) biri de domates atıklarıdır. 2015 yılında Türkiye'de üretilen toplam domates miktarı 8.170 .000 ton/yıl olarak belirlenmiştir[7]. Domates atıklarından oluşan atık miktarı yaklaşık olarak \% 14 civarındadır[8]. Yani; Türkiye' de domates atıklarından oluşan domates atık miktarı yaklaşık olarak 584.000.00 ton/yıl olmaktadır. Bu potansiyel değerler, uygun kapasitede biyogaz tesislerinin işletilebilmesine uygun görülmektedir. Bu çalışmada, domates atıklarının biyogaz ve metan üretim değerleri belirlenmiştir. Bu kapsamda, söz konusu atıklar toplanarak laboratuvar ortamında kurutulup ögütülmüştür. Ögütülen atıklardan alınan örneklerin, kuru madde ve organik madde analizleri yapıldıktan sonra deneysel olarak biyogaz ve özgül metan üretim değerleri "Hohenheim Batch Test" yöntemi ile belirlenmiştir[9].

\section{Materyal Ve Yöntem}

Materyal olarak domates atıkları ele alınmıştır. Denemeler, Stuttgart Hohenheim Üniversitesi, Tarım Makineleri ve Biyoenerji Mühendisliği Biyogaz Araştırma laboratuvarında yürütülmüştür. Alınan atıklardan yaklaşık bir kilogramlık numune kurutma fırınında 50-60 0C sıcaklık değerlerinde kurutulmuştur. Kurutulmuş domates atıkları, Vorwerk Thermomix Tm 31 sanayi tipi ögütücü kullanılarak, standart (VDI 4630, 2006) gereği $1 \mathrm{~mm}$ boyutunda öğütülmüştür[10].

Öğ̈̈tülmüş domates atıklarının standart gereği (VDI 4630, 2006); 550 0C'de ham kül içeriğini belirlemek için Heraeus marka kül fırını, 105 0C'de kuru madde içeriğini belirlemek için ise Memmert marka etüv kullanılmıştır.

Kuru madde analizinde porselen krozeler boş olarak etüvde $105^{\circ} \mathrm{C}^{\prime}$ de 1 saat bekletilmiştir. Daha sonra desikatöre alınarak oda sıcaklığına kadar soğutulmuştur. Mikro terazide boş olarak kütlesi ölçülen porselen krozeler (A) içerisine, her atık için yaklaşık $1 \mathrm{~g}$ konularak tartılmıștır (B). İçerisinde örnek 
bulunan krozeler etüve yerleştirilerek $105^{\circ} \mathrm{C}^{\prime}$ de firında 4-6 saat yakılmıştır. Bu süre sonunda desikatöre alınan porselen krozeler oda sıcaklığına kadar soğutulmuş ve mikro terazide tartımı yapılmıştır (C). Bulunan sonuçlar eşitlik 1'de [11-21] yerine konularak örneklerin kuru madde içeriği hesaplanmıştır.

$\mathrm{KM}=(\mathrm{C}-\mathrm{A}) / \mathrm{B} * 100$

Burada;

KM : Kuru madde içeriği (\%),

A : Boş porselen kroze kütlesi (g),

B $\quad: 1 \mathrm{~g}$ deneysel atık materyali ilave edilmiş porselen kroze kütlesi (g),

C : Etüv sonrası porselen kroze kütlesi (g)'dir.

Ham kül ve organik madde analizinde, porselen krozeler boş olarak ham kül firınında $550{ }^{\circ} \mathrm{C}^{\prime}$ de 2 saat bekletilmiş ve bu işlemden sonradesikatöre alınarak oda sıcaklığına kadar soğutulmuştur (VDI 4630, 2006). Mikro terazide boş olarak kütlesi ölçülen porselen krozeler (A) içerisine yaklaşık, her bir atık materyalden $1 \mathrm{~g}$ konularak tartılmıştır (B). İçerisinde atık materyal bulunan krozeler ham kül fırınına yerleştirilerek $550^{\circ} \mathrm{C}$ 'de 6-8 saat yakılmıştır. Fırın, belli sıcaklığa kadar soğuduktan sonra desikatöre alınan krozeler oda sıcaklığına kadar soğutulmuş ve mikro terazide tartımı (C) yapılmıştır. Bulunan sonuçlar eşitlik 2 ve 3'de yerine konularak örneklerin ham kül ve organik madde içeriği (AOAC, 1990) hesaplanmıştır.

$\mathrm{HK}=\left((\mathrm{C}-\mathrm{A}) / \mathrm{B}^{*} 100\right)$

$\mathrm{OM}=100-\mathrm{HK}$

Burada;

HK : Ham kül içeriği (\%),

A : Boş porselen kroze kütlesi (g),

B : $1 \mathrm{~g}$ deneysel atık materyali ilave edilmiş porselen kroze kütlesi (g),

C : Firınlama sonrasi porselen kroze kütlesi (g),

OM : Organik madde içeriği (\%)'dir.

Standart gereği anaerobik ortam koşullarının biyogaz oluşumuna uygunluğunu belirlemek amacıyla aşı (inokulum) hazırlanmıştır. Sıvı+katı fazda bir karışım olan inokulum, Hohenheim Üniversitesi biyogaz laboratuvarındaki bir tank içerisinde hazırlanmıştır. Karışım, $37{ }^{\circ} \mathrm{C}^{\prime}$ sıcaklıkta 300 L'lik tanka boşaltıldıktan sonra içeriğini dengede tutmak için günlük $18 \mathrm{~g}$ başak özü, $18 \mathrm{~g}$ mısır $10 \mathrm{~g}$ soya, $12 \mathrm{~g}$ kolza yağı ve belli miktar su eklenerek stabilize edilmiştir (VDI 4630, 2006).

Öğütülmüş materyallerden her birinden 3'er örnek alınıp, her örnek 0.2 g olacak (VDI 4630, 2006) şekilde $\pm 0.1 \mu \mathrm{g}$ çözünürlüğe sahip Kern EG 4200-2 NM marka mikro terazide tartıldıktan sonra 100 mL'lik cam şırıngalara özel kaşıklar yardımıyla konularak, şırınga örnekleri inkübatör (Şekil 1) içindeki bölmelere yerleştirilmiştir. Aynı şekilde deney koşullarının standart değerlerde olup olmadığını kontrol etmek için her biri $30 \mathrm{~mL}$ inokulum alacak şekilde büret kullanılarak hazırlanan 3 adet inokulum 
şırıngası da inkübator içindeki bölmelere yerleştirilmiştir. Hohenheim batch test şırıngası (Şekil 2) kullanılmıştır

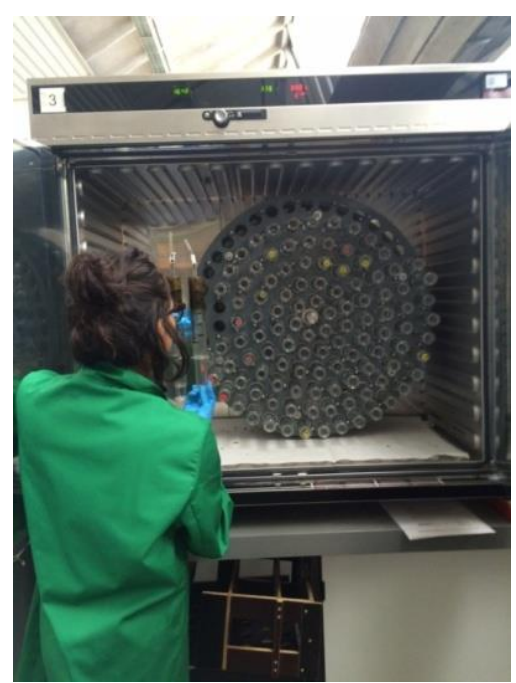

Şekil 1. İnkubator iç görüntüsü

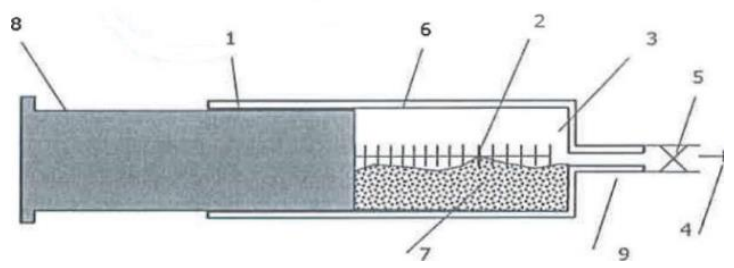

Şekil 2. Hohenheim batch test şırıngası (VDI 4630, 2006)

1: Kayma ve sizdırmazlık aracı

2: $1 \mathrm{~mL}$ 'lik bölme

3: Gaz haznesi

4: Gaz analizi için açıklık

5: Kelepçe

6: Cam şırınga

7: Fermantasyon maddesi

8: Piston

9 : İnce boru

Standart (VDI 4630, 2006) gereği, şırıngalara tartılan örnekler konulmadan önce şırınga pistonu çıkarılıp, enjektörlerin uç kısmında bulunan ve gaz transferinde kullanılan silikon hortumlara plastik klipsler takılmıştır. Enjektörlerin pistonlarına, analiz esnasından gaz kaçırmasını önlemek amacıyla, alttan ve üstten 3'er parmak boşluk kalacak şekilde vazelin sürülmüştür. Daha sonra cam şırınga pistonları takılıp, klipsler kapatılarak kullanıma hazır hale getirilmiştir. Şırıngalara inokulum konulduktan sonra $37 \mathrm{oC}$ sicaklıkta olan inkübator içerisine yatay bir şekilde yerleştirilmiştir. İnkübatorde bulunan çember içindeki şırınga yuvalarına yerleştirilen şırıngalardaki materyallerin üniform şekilde olması için çemberin $10 \mathrm{~d} / \mathrm{d}$ hızda dönmesi sağlanmıştır. İnkübatorde işlemler başlamadan önce metan içeriğini belirlemek için kullanılan metan ölçüm düzeneği kalibrasyon tüpü (\% 
60.5 CH4) ile kalibre edilmiştir. Kalibrasyonun amacı, ölçülen gazın standart koşullarda (0 0C ve 1013 $\mathrm{hPa}$ ) olduğunu doğrulamaktır. Deneyde, 35 gün süre boyunca ölçüm yapılmıştır. Ölçümler, ilk 6 gün için her 6 saatte bir, daha sonraki günlerde 8 ve 12 saat arayla yapılarak her bir örnekte oluşan biyogaz ve metan üretimleri belirlenmiştir. Biyogazdan oluşan metan değerlerinin ölçümü, cam şırıngalar içerisinde $20 \mathrm{~mL}$ düzeyine erişildiğinde, metan okuma düzeneği tarafindan gerçekleştirilmiştir (VDI 4630, 2006).

Ele alınan domates atıklarının her bir örneği için hazırlanan cam şırıngalar içerisinde üretilen gazın normal hacminin hesaplanması için eşitlik (4), oluşan biyogazın metan içeriğinin belirlenmesinde eşitlik (5), zamanla kümülatif olarak biriken metan gazının hesaplanması için ise eşitlik (6) kullanılmıştır (VDI 4630, 2006).

$V_{0}^{t r}=V\left(\frac{\left(\mathrm{P}-\mathrm{P}_{\mathrm{w}}\right)\left(\mathrm{T}_{0}\right)}{\left(\mathrm{P}_{0}\right)(\mathrm{T})}\right)$

Burada;

$V_{0}^{t r} \quad$ : Normal şartlar altındaki gazın hacmi $\left(\mathrm{mL}_{\mathrm{N}}\right)$,

$V$ : Okunan gazın hacmi (mL),

$\mathrm{P}$ : Okuma yapılan zamandaki hava basincı $(\mathrm{hPa})$,

$\mathrm{P}_{\mathrm{w}} \quad$ : Dış ortamda bulunan sudaki sıcaklığın buhar basıncı (hPa),

$\mathrm{T}_{0} \quad$ : Normal sicaklik $(273 \mathrm{~K})$,

$\mathrm{P}_{0} \quad$ : Normal basinç $(1013 \mathrm{hPa})$,

$\mathrm{T}$ : Dış ortamda fermantasyona uğramış gazın sıcaklığı (K)'dır.

$C_{C H_{4}}^{t r}=C_{C H_{4}}^{f}\left(\frac{P}{\left(P-P_{w}\right)}\right)$

Burada;

$C_{C H_{\Delta}}^{t r} \quad$ : Kuru biyogaz içinde bulunan hacimsel metan içeriği (\%),

$C_{\mathrm{CH}_{\Delta}}^{f} \quad$ : Nemli biyogaz içinde bulunan hacimsel metan içereği (\%),

P : Okuma esnasındaki gaz basıncı (hPa),

Pw : Dış ortamda bulunan sudaki sıcaklığın buhar basıncı (hPa)'dır.

$M_{C_{4}}(t)=M_{C H_{4}}(0)+\int_{t_{1}}^{t_{2}} M_{C H_{4}}(t) d t$

Burada;

$M_{\mathrm{CH}_{4}}(t)$ : Kümülatif metan üretimi $\left(\mathrm{Nm}^{3} \mathrm{CH}_{4} / \mathrm{kg} \mathrm{OKM}_{\text {in }}\right)$,

$M_{\mathrm{CH}_{4}}(0): \mathrm{t}=0$ iken metan üretimi $\left(\mathrm{Nm}^{3} \mathrm{CH}_{4} / \mathrm{kg} \mathrm{OKM}_{\text {in }}\right)$,

$\mathrm{t}_{2}-\mathrm{t}_{1} \quad$ : İki ölçüm arasındaki süre (min)'dir.

Domates atıklarından alınan örneklerden deneysel olarak belirlenen kuru madde (KM), organik kuru madde $(\mathrm{OKM})$ ve 3 tekerrürlü örneklerden ölçülen biyogaz ve metan değerleri çizelge ve şekillere aktarılarak yorumlanmıştır. 


\section{Bulgular}

\subsection{Domates Atıklarının Kuru Madde ve Organik Kuru Madde Oranları}

Domates atıkların; kuru madde oranları \% 84.9 organik kuru madde oranları $\% 88.7$ olarak belirlenmiştir (Tablo 1).

Tablo 1. Domates atıklarının kuru madde (KM) ve organik kuru madde (OKM) oranları

\begin{tabular}{cccc}
\hline Attklar & Boyut & KM (\%) & OKM (\%) \\
\hline Domates & $1 \mathrm{~mm}$ & 84.9 & 88.7 \\
\hline
\end{tabular}

\subsection{Domates Atıklarının Metan Üretim Değerleri}

Deneysel olarak yapılan bu çalışmada, öncelikle standart (VDI 4630, 2006) gereği anaerobik ortam koşullarının biyogaz oluşumuna uygunluğunu belirlemek amacıyla inokulum'un metan üretim değerleri belirlenmiştir. Daha sonra ise ele alınan domates atıklarının metan üretim değerleri gerçekleştirilmiştir. Deney standardı (VDI 4630, 2006) gereği inokulum'dan oluşacak kümülatif özgül metan üretiminin 0$0.1 \mathrm{Nm} 3 / \mathrm{kg}$ OKM olması gerekmektedir. Bu çalışmada, inokulum'dan açığa çıkan maksimum kümülatif özgül metan üretimi $0.09 \mathrm{Nm} 3 / \mathrm{kg}$ OKM olarak belirlenmiştir. Zamana bağlı olarak inokulum'dan meydana gelen kümülatif metan üretimi 1. günde başlamakta, günlere göre giderek artmakta ve maksimum değere 30-35. günlerde ulaşmaktadır (Şekil 3). İnokulum'daki metan değerlerinin başlangıçta düşük olmasının nedeni anaerobik (oksijensiz) parçalanma için zamana ihtiyaç duyulmasidir.

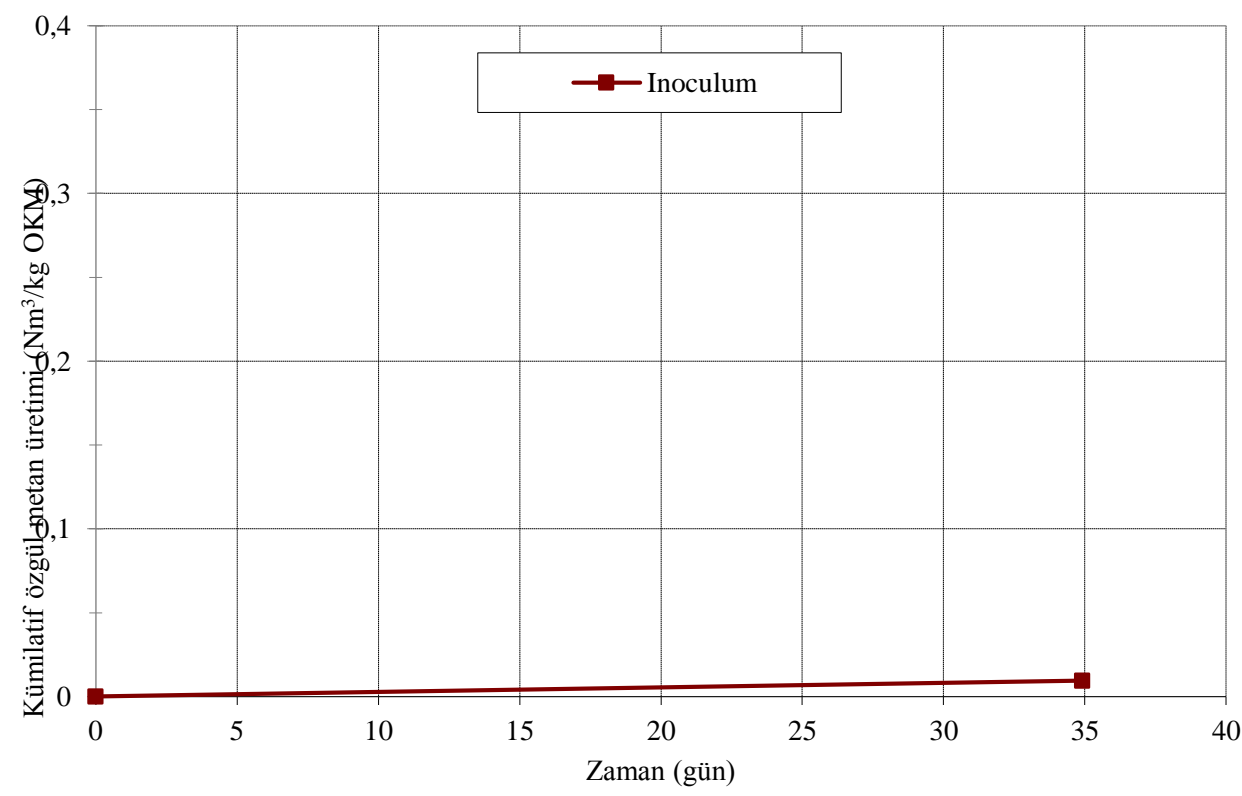

Şekil 3. İnoculum'un özgül kümülatif metan üretimi 
Zamana bağlı olarak, domates atıklarından oluşabilecek kümülatif özgül metan üretimi, her üç örnek için 1-15 günleri arasında giderek artmakta, 15-35 günleri arasında artış hızı azalmakta ve 35. günde maksimum değerlere ulaşmaktadır. 15-35 günlerinde metan üretimi, en fazla 2 . örnekte $(0.38 \mathrm{Nm} 3 / \mathrm{kg}$ OKM), en az ise 3. örnekte $(0.36 \mathrm{Nm} 3 / \mathrm{kg}$ OKM $)$ gerçekleşmektedir. 35. günde her üç örneğin de ortalama kümülatif özgül metan üretim değerleri 0.37 Nm3/kg OKM olmaktadır (Şekil 4.5).

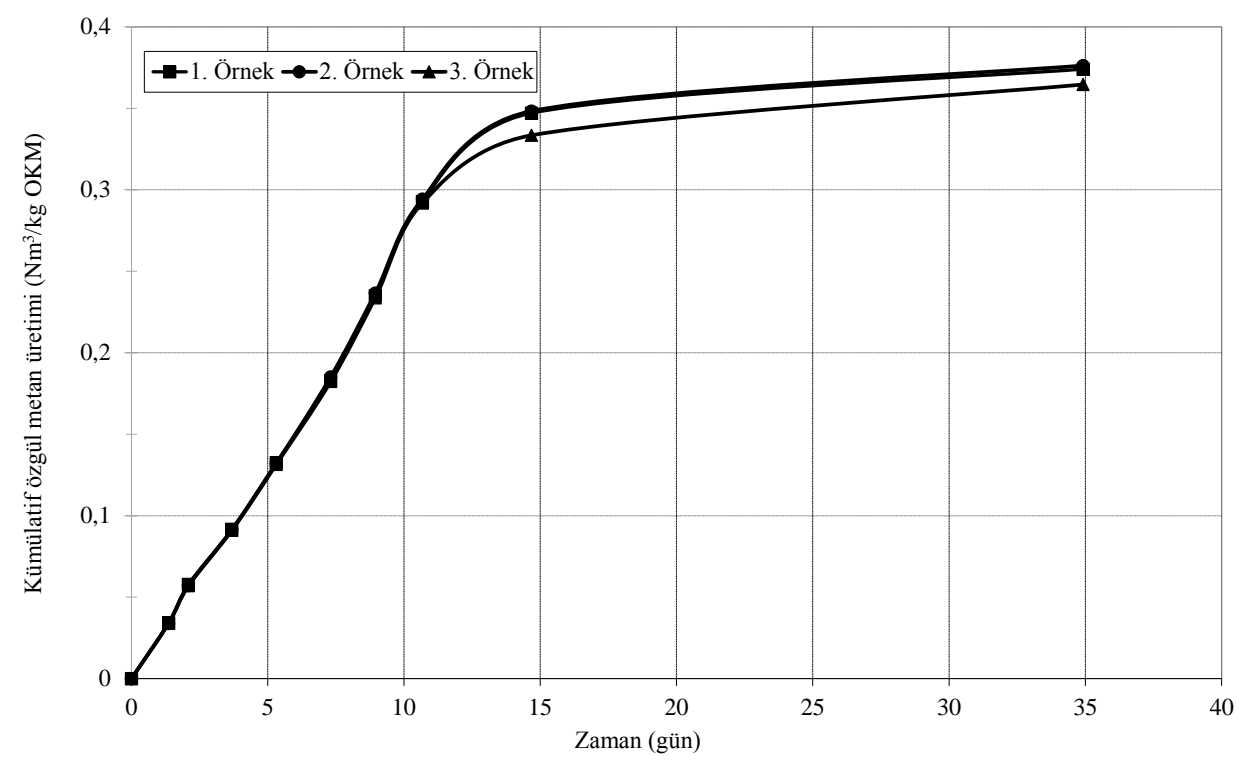

Şekil 41.1 mm boyutunda domates atıklarının kümülatif özgül metan üretimi

\subsection{Domates Atıklarının Biyogaz Üretim Değerleri Ve Metan İçerik Oranları}

Domates atıklarının kümülatif özgül biyogaz üretiminin ortalama değeri 0,692 Nm3/kg OKM, biyogazın metan içeriğinin ortalama değeri ise \% 54 olarak belirlenmiştir (Tablo 2).

Tablo 2. Domates atıklarının metan içerik yüzdeleri ve biyogaz verimleri

\begin{tabular}{cccc}
\hline Atıklar & Numune & $\begin{array}{c}\text { Biyogaz üretimi } \\
\left(\mathbf{N m}^{\mathbf{3}} / \mathbf{k g ~ O K M}\right)\end{array}$ & $\begin{array}{c}\text { Metan } \\
\text { içeriği } \mathbf{~ ( \% ) ~}\end{array}$ \\
\hline \multirow{4}{*}{ Domates } & 1.Örnek & 0,695 & 54 \\
& 2.Örnek & 0,694 & 54 \\
& 3.Örnek & 0,687 & 53 \\
& Ortalama & 0,692 & 54 \\
\hline
\end{tabular}

Yapılan Bazı Çalışmalarda Atıklardan Elde Edilen Biyogaz Değerleri Organik atıklardan deneysel ve teorik yöntemlerle biyogaz elde edilmesine ilişkin yapılan bazı araştırma sonuçları Tablo 3 'te verilmiştir. 
Tablo 3.Biyogaz ile yapılan diğer çalışmalar

\begin{tabular}{|c|c|c|c|}
\hline Araştırmacı & Ele alınan atık materyal & $\begin{array}{l}\text { Biyogaz değeri } \\
\text { belirleme yöntemi }\end{array}$ & $\begin{array}{l}\text { Biyogaz değeri } \\
\left(\mathrm{Nm}^{3} / \mathrm{kg} \mathrm{OKM}\right)\end{array}$ \\
\hline (Lane., 1984) & Karışık sebze-meyve & Deneysel & $0.429-0.568$ \\
\hline (Prema ve ark.,1992) & Karışık sebze-meyve & Deneysel & $0.5-0.6$ \\
\hline $\begin{array}{l}\text { (Mtz.-Viturtia ve ark., } \\
\text { 1995) }\end{array}$ & Karışık sebze-meyve & Deneysel & $0.2-0.63$ \\
\hline $\begin{array}{l}\text { (Bouallagui ve ark., } \\
\text { 2003) }\end{array}$ & Karışık sebze-meyve & Deneysel & 0.707 \\
\hline (Qiao ve ark., 2011) & Karışık sebze-meyve & Deneysel & 0.443 \\
\hline (Gül., 2014) & Karışık sebze-meyve & Teorik & $0.27-0.34$ \\
\hline (Hutnan ve ark.,) & Misır silaj1 & Deneysel & 0.655 \\
\hline (Frauke ve ark., 2015) & Hayvan gübresi & Deneysel & 0.471 \\
\hline
\end{tabular}

$\mathrm{Bu}$ çalışmada, domates atıklarından elde edilen biyogaz değerlerinin birçok atı̆ga göre önemsenecek düzeyde olduğu görülmektedir.

\section{Sonuçlar}

Domates atıkların biyogaz üretim değerlerinin belirlenmesine yönelik yapılan bu araştırmadan elde edilen sonuçlar ve öneriler aşağıdaki gibi özetlenebilir:

- Domates kuru madde oranı \% 84.9 ve organik kuru madde oranı \% 88.7olarak saptanmıştır.

- $\quad$ Kırmızı biber atıklarının; ortalama kümülatif metan üretimi $0.37 \mathrm{Nm} 3 / \mathrm{kg}$ OKM, ortalama kümülatif biyogaz üretimi $0.692 \mathrm{Nm} 3 / \mathrm{kg}$ OKM ve metan içerik oranı ise $\% 54$ olarak belirlenmiştir.

- Domates atıklarının biyogaz üretim potansiyelleri yüksek düzeyde bulunmaktadır. Bu nedenle biyogaz tesisleri için önemli materyaller olduğu söylenebilir.

- Söz konusu atıkların biyogaz amaçlı kullanılması durumunda ortaya çıkacak yeni atıkların tarımda organik gübre amaçlı kullanımı sağlanabilir.

- Atıklardan atmosfere metan ve amonyum olarak salınacak hava kirliliği, atıkların biyogaza dönüştürülüp kullanılmasıyla önlenebilecektir.

- $\quad$ Atıkların bertaraf edilmesi sonucunda havadaki koku yoğunluğu azalacak ve çevresel sorun da azaltılabilecektir.

- $\quad$ Atıkların bertaraf edilmesi sonucunda havadaki koku yoğunluğu azalacak ve çevresel sorun da azaltılabilecektir.

- $\quad$ Organik atıklar biyogaz tesislerinde işlenerek hem çevre dostu enerji üretilebilir hem de ekonomiye katma değer sağlanabilir.

- $\quad$ Türkiye'deki biyokütle enerji potansiyeli, bu enerjinin kullanım oranı ve çevresel etkileri konusunda yapılacak çalışmalar bu alanda veri tabanını güçlendirecektir.

- Günümüzde birçok ülkede, biyogazın ekonomik ve çevresel önemi benimsenmiş ve uygulamaları başlatılmıştır. Türkiye'de ise bu uygulamalar henüz beklenen düzeye ulaşmamıştır. Konuya ilişkin, daha yoğun olarak yapılacak araştırma ve uygulamalar ile bilgi ve teknolojiler yaygınlaşabilecektir. 


\section{Kaynakça}

[1] Deublein, D., Steinhauser, A., (2008). Biogas from Waste and Renewable Resources, p.1-450.

[2] Anonim, 2006. Türkiye'nin Yenilenebilir Enerji Kaynakları. Türkiye Çevre Vakfi, Yayın No:175, 368s, Ankara.

[3] Acaroglu, M., 2007. Renewable Energy Sources (Turkish). 2nd ed. Nobel Yayınevi, ISBN 978 605-395-047-9, 609, Ankara.

[4] Akova, İ., 2008. Yenilenebilir Enerji Kaynakları. Nobel Yayın No: 1294, 224s, Ankara.

[5] Arkutman, F., 2003. “Atıksu Arıtımı ve Arıtma Teknikleri”, Bilim ve Teknik, 428:42- 52.

[6] Anonim, 2012. Technical Documentation. Vorwerk Thermomix Tm 31. User Manuel. Mixer, Vorwerk International Strecker \& Co., Switzerland.

[7] AOAC.,1990. Official Methods of Analysis. 15th ed. Association of Official Analytical Chemists, Washington, DC.US.

[8] Fanchi, J. R., 2011. Energy in the 21st Century. World Scientific Publishing Co. Pte. Ltd. 5 Toh Tuck Link, Singapore 596224.

[9] Heffrich, D., and Oechsner, H., 2003. Comparison of Different Lab $\neg$ oratory Techniques for the Digestion of Biomass, Landtechnik, 9, 27-30.

[10] Kapluhan, E., 2014. Enerji Coğrafyası Açısından Bir İnceleme: Biyokütle Enerjisinin Dünyadaki ve Türkiye'deki Kullanım Durumu. Marmara Coğrafya Dergisi, (30):.97-25.

[11] Öztürk, H. H., 2008. Yenilenebilir Enerji Kaynakları ve Kullanımı. Teknik Yayınevi, 367s, Ankara.

[12] TUIK, 2015. Türkiye İstatistik Kurumu. Konularına Göre İstatistikler, Tarım. https://biruni.tuik.gov.tr/bitkiselapp/bitkisel.zul st (Erişim: 15.11 2016).

[13] URL., 2016. Meyve ve Sebze Atıklarının değerlendirilmesi. http://foodwastefruit.tripod.com/id1.html (Erişim: 15.11.2016)

[14] Lane, A., 1984. Laboratory Scale Anaerobic Digestion of Fruit and Vegetable Solid Waste. Biomass, 5:245-59.

[15] Prema, V., Sumithra, S., Krishna, N., 1992. Anaerobic of Fruit and Vegetable Processing Wastes for Biogas Production. Bioresource Technology, 40:43-8.

[16] Mtz.-Viturtia A., Mata-Alverez J. and Cecchi F. 1995. Two-phase Continuous Anaerobic Digestion of Fruit and Vegetable Wastes, Resources. Conservation and Reycling, 13, 257-267.

[17] Bouallagui, H., Ben Cheikh, R., Marouani, L., Hamdi, M., 2003. Mesophilic Biogas Production From Fruit And Vegetable Waste İn Tubular Digester, Bioresour. Technol., 86, 85-90.

[18] Qiao, W., Yan, X., Ye,J., Sun, Y., Wang, W., Zhang, Z., 2011. Evaluation Of Biogas Production From Different Biomass Wastes With/Without Hydrothermal Pretreatment, Renewable Energy, 36, 3313-3318. 
[19] Gül, A., 2014. Sebze ve Meyve Atıklarının Biyogaz Üretim Potansiyelinin Belirlenmesi. Yüksek Lisans Tezi, Gazi Üniversitesi Fen Bilimleri Ensitütüsü, Çevre Bilimleri Anabilim Dalı.

[20] Hutnan, M., Spalkova V., Bodik I., Kolesarova N., Lazor M., 2009. Biogas Production from Maize and Maize Silage. Polish Journal of Evrironmental Studies, 19, 323-329.

[21] Frauke, H.K., Susanne, O., Ebenhard, H., 2015. Effect on The Biogas and Methane Production of Cattle Manure Treated with Urease İnhibition. Journal of Biomass and Bioenergy. ISBN 0961$9534,75-82$. 